arm when raised falling powerless by his side. The nail was quickly removed by the same method as the other, but without producing the slightest appearance of pain; in both operations the feet and legs ware purposely left free from restraint; in fact, they were not tonched except by the operator, who merely steadied the toes whilst doing the operations, so that muscular twitching, or similar evidence of pain, might easily have been observed: but during the removal of the second nail there was not the slightest sign, either of twitching of the toes or con traction of the muscles of the leg, whilst the countenance re mained unchanged. A towel was then thrown over his feet, to obscure them from his view when he recovered from the insensibility, in which he continued for several minutes after the operation was completed. For the first four minutes after the second inhalation, he was in a state of complete coma accompanied by stertorous breathing, but his pulse beat quietly, at about 60 . At the expiration of this time, he sat up on the mattrass, and addressed Mr. Hancock as a noble lord, in whose service he had formerly lived, remonstrating against his dismissal, and asserting that it was caused by the jealousy of the steward-that he liked his lordship and her ladyship very well, and that his place was the most comfortable of any he had ever been in. He continued upon this topic for about ten minutes, occasionally falling back upon his pillow for a second or two, and then raising hinself up, and staring wildly around him. He afterwards became sufficiently rational to answer questions; and upon being asked whether he was ready to undergo the operation, he said he was, and told Mr. Hancock he might begin; when, being shown his toe, and informed that the nail had already been removed, he expressed great satisfaction, declaring he had felt no pain, and was totally unconscious of anything having been done. Wet lint was applied to the wounds, and the patient sent to bed.

His pulse, during the first inhalation, remained natural, at 90 , and continued so until about the middle of the second inhalation, when it dropped to 60 , and became small; as he recovered consciousness, it gradually returned to its natural standard. His conjunctivæ were slightly congested, but not particularly so, and his pupils natural, the irides acting when exposed to the light. When the patient sat up, and the eyes were shaded from the light by his projecting brows, the pupils were about one-fifth of an inch in diameter; but when he lay upon his back, with the eyes exposed to the full glare of light from the skylight of the theatre, the pupils then contracted to less than one-eighth of an inch in diameter. His skin retained its natural temperature throughout. Upon being carried up stairs, he was immediately placed in a warm bed, as he complained of feeling very cold. In his answers to questions, he was at first rather incoherent, and evidently confused, not having the slightest idea where he was. Some hot wine-and water was given to him, which he swallowed without any diffculty, and wrapping his head in the bedclothes, begged not to be disturbed, as his head ached very much. About an hour after the operation he appeared much more sensible, but still had head. ach, with some confusion about what had been done and where he was; noise and light distressed him; he did not sleep, but appeared to be suffering from a preternatural degree of sensibility. After two hours he appeared quite recovered. He laughed when told of his conduct in the operating theatre, and corroborated all that he had said during the time. He had lived with a nobleman some time ago, and had been parted with on account of a disagreement with the steward. He got up to take lis food, and subsequently passed a good night, not requiring any sedative whatever. Next morning, not feeling any uneasiness, and being desirous of reaching his home, in order to take his part in the duties of his situation, he left the hospital and walked to Suffolk-place, (his residence,) suffering no inconvenience from the effects of the operation.

He was seen on Sunday, and was then going on perfectly well. The apparatus employed upon this occasion was one made by Mr. Weiss; it is very convenient and portable, and certainly proved most efficient. Had the operation required a quarter of an hour, it might have been performed without any further inhalation, so completely was the patient under the influence of the vapour.

OPERATIONS FOR STRABISMUS.

SrR,-Though the utility of sulphuric ether in producing insensibility to pain has been pretty clearly substantiated, it may nevertheless not be uninteresting or unprofitable to add to the testimony which has already appeared in its favour. No remedy probably has ever been proposed capable of producing such astounding, such gratifying effects, and few, in deed, have in so short a time so fully realized the promises which have accompanied their announcements. As the process is only just in its infancy, $I$ cannot but imagine that every fact relating to it must be of importance in enabling the profession to form an opinion of its merits, and to judge accurately of the extent and cajabilities of what promises to be one of the greatest boons ever conferred on humanity. With this view, I beg to state the result of two operations for strabismus, (in which I was assisted by my friend Mr. Ilarris, performed after "letheonizing" the respective patients. They were both boys, about nine years of age. The first, after inhaling the ether from a common bladder for two or three minutes, fell back in his chair, and appeared to be completely under its influence. The operation was jroceeded with. At the nnoment of dividing the tendon, he uttered a firint "oh!" and shortly after awoke, as it were in a state of surprise. On being asked if he felt much pain, he said that $I$ had " pricked his eye." The slightness of his suffering may be judged of from his immediately consenting to have his other eye operated upon, which, under ordinary circumstances, few or no youthful subjects would submit to. This, however, was not deemed advisable. The second case was less satisfactory. The patient inhaled the vapour for several minutes, then stared about him in a vacant manner, and was so far insensible as not to complain of pain on being sharply vinched. The operation was proceeded with, and though the signs of suffering were not to be mistaken, he nevertheless made much less resistance than is usually met with in children; and on being questioned afterwards, said the pain was not great. As the whole of the tendon did not appear to be divided, it was necessary to reintroduce the blunt hook, and incise a small portion which had escaped. This second incision, he stated, was much inore painful than "all the rest."

From the result of these cases, I cannot but conclude that we are in possession of a most powerful means of alleviating human suffering, and am of opinion that it will be found of especial utility in operating on young subjects, whose struggles during the performance of an operation are generally the greatest difficulty the surgeon has to contend with. I may mention, that neither nausea, vomiting, nor any other disagreeable effect was produced in either instance.-I am, Sir, your obedient servant,

Kirkdale, Liverpool, Jan. 1847 .

Edward Parker,

Surgeon to the Industrial School.

\section{OPERATIONS ON THE TEETH.}

SIR,-I have used the vapour of ether, in seventy cases, for procuring insensibility to pain, during the extraction of teeth, with the varions apparatus recommended for that purpose, and kindly supplied by Mr. Fergnson, instrument-maker to the hospital. I can bear testimony to their general efficacy in all cases where the vapour has been properly inhaled. As my experience increased, $I$ could not but observe the inconvenient size and costliness of the various apparatus, conpled with the expense of preparing them for use; and as economy and convenience must be considered in that which will become general, my thoughts were directed, like those of many others, to the production of an apparatus which would at once combine simplicity with utility; and as hookahs have been chosen as the fashionable shapes, so mine bcars some resemblance to a German pipe, and has been found efficient. The pipe is of glass, and mounted at the top with a brass cap and stopcock, into which an elastic tube is screved, of six. teen inches in length, which is surmounted by a doublevalved mouthpiece, of the description in ordinary use, a steel compress, padded, being used for securing the nostrils. It has been hinted to me, that a valve made of some fine tissue, and secured to the top of the mouth-cal, wonld be an improvement on the compress in general use, as many patients dislike their noses being secured by such an instrument. As much ether may be poured into the pipe as will fill the well and saturate the sponges. The mouthpiece should be placed between the patient's teeth, the stopper should be removed, and the stopcock turned on, when the patient should be directed to inhale in a natural way. The operator will derive a great advantage in the use of this apparatus, as he will perceive the rising of the fluid in the tube, as the air passes in at each inhalation-a means which will greatly aid his judgment as to the probable effect of the vapour on the patient's system. I have performed more than twenty operations with this apparatus, making, in the whole, above ninety cases; and I can with safety affirm, that this has answered better than any other I have used.

It was again tried, in an operation (likely from its character to be a protracted one) performed here by Mr. Skey, on Saturday, the 16th. A boy, aged ten years, met with an ac- 
cident five weeks since, by which he ruptured his urethra: it was followed by an abscess, and almost entire closure of the canal. Mr. Skey, after some difficulty, succeeded in perfecting the communication of the soparated portions of the tube. The operation occupied twenty-five minutes, during the whole of which time the patient was insensible to pain. I need scarcely observe, that he inhaled the vapour, at intervals, during the whole time; and before being taken out of the theatre, exclaimed to the question, "Have you suffered pain?" "No; he put something into my mouth which sent me to sleep!" I may here add, that the patient is doing well.-I remain, Sir, your obedient servant,

st. Bartholomew's Hospital,

S. J. TrACY. January, 1847.

N.B.-The apparatus described was manufactured by $\mathbf{M r}$. D. Ferguson, instrument-maker to the hospital.

\section{RENIOVAL OF A TUMOUR}

By Joins Charles Hali, M.D., M.R.C.S., East Retford.

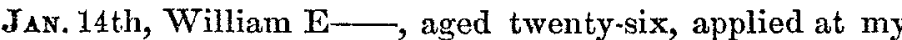
house for the purpose of having a small fatty tumour, about the size of an egg, removed from his neck. Mr. Cocking, one of the medical officers of the Hull Dispensary, was present during the operation. The man was placed in an arm-chair, and the vapour applied by means of an instrument. which was supplied to me by Mr. Hooper, the operative chemist, and is the one figured in Tre LANCET of last week, and is certainly very complete, and well adapted for the purpose. He complained, at the first, of a slight tickling sensation in the throat: this soon went off; in two minutes, the pulse had risen to 135 ; in another minute, his arm was slightly raised; his feet were then extended, and he fell back in his chair in a complete state of insensibility. The tumour, being somewhat adherent, required a good deal of dissection to separate it from the surrounding parts. The operation occupied about three minutes; and in about another minute, the man awoke, declaring he had "felt no pain"" and it took some little time to convince him the operation had been performed. During the operation, he raised the leg once, but said he had felt no pain at all: he had been in a dream.

There is a class of cases in which the vapour has not yet been tried; and from my experience in one case, $I$ am led to recommend it with confidence to the members of my profession. I allude to retention of urine from spasmodic stricture of the urethra: in such cases it will, I think, be found an effectual and elegant substitute for the warm bath, opium, bleeding - the whole paraphernalia of the former plan of treatment. In the case to which I allude, all attempts to pass a catheter were useless. On applying the vapour, the patient passed into a state of insensibility in five minutes; and during his dreamy unconscfousness, a catheter was passed without any pain, the bladder emptied, and on coming round, he got up perfectly free from pain, although previously in the greatest agony from an overloaded bladder. I have every reason for thinking the application of the ether vapour will be attended with the greatest possible benefit to those unhappy patients who may be suffering from the torments unrelieved retention of urine causes, and have therefore embraced the earliest opportunity of making the result of my experience known to the profession. We all know the difficulty of passing a catheter in these cases-a difficulty which I hope will now, in the majority of them, be removed.

Grove-street, East Retford, Jan, 1847.

\section{THE OPERATION FOR PTOSIS.}

To the Editor of THe LANCET.

Sir,-Some years ago, I performed the operation for ptosis, described by Dr. Brett in your last number; but resolved never to have recourse to it again, should similar cases present themselves to my notice. My patient was in a much worse predicament after than before the operation, in consequence of the want of protection to the ball of the eye from dust, flies, \&c., the intolerable annoyance of which is infinitely greater than the evil of a closed eyelid. My patient never forgave me.-I am, Sir, yours,

C. R. BREE.

Stowmal ket, Dec. 1847 .

* The first evening $\mathrm{I}$ received the instrument from Mr. Hooper, not having a patient to practise upon, and wishing to try the effects of the vapour, applied the tube to my own mouth. I had not tried it long, before I f back in my chair, and remained in a dreany state for some little time. When 1 awoke, $I$ was not for a moment aware of what had taken place, phil the sight of the instrment recalled it to

\section{PATENT HUMANITY.}

To the Editor of Tine Lanoet.

Sin,-I am a constant reader of The Larret, in conmon, as I believe, with many other members of the bar. As your reader, $I$ could not but take considerable interest in the new application of ether for the purpose of procuring insensibility during surgical operations; and as a lawyer, my attention has been equally arrested by the attempt which scems to be making to degrade a noble discovery to the level of a quack medicine. I agree with you, that a testimonial is due to the discoverer; but let us distinguish between the discoverer and the speculator, and let the interests of humanity and the claims of genins walk hand in hand. It is the duty of the pliysicians and surgeons of our public hospitals to vindicate both; and it is your province not to snffer either question to die.

But, with regard to the patent, it is said, on the one hand, that the discovery is not susceptible of such a thing; and, on the other, that no one can tell whether the patent can be sustained or not, until the specification, not yet lodged, has been examined. Nor, I may add, can there be any proceeding for sustaining the patent, until that specification be lodged: in fact, there is no patent until then. But although it be very true that, with regard to the specific letters in question, no opinion could now be adventured on whether they could be supported or not, it is equally true that, for all the purposes of the argument, enough exists in the patent law itself to warrant the decided opinion, that no extent of legal ingenuity could frame a specification which could prevent a medical man from procuring insensibility by administering ether, or from cutting off a leg or an arm, or performing any other surgical operation during such insensibility.

We need not go, although they are not unimportant to the question, to the general conditions, subject to which all patents are granted, to prevent their abuse, in proof of this; for the direct condition is decisive of the point. The patent must be in respect of a manufacture, as that mannfacture must be new. You cannot have a patent of a principle; you cannot have a patent of a result, except with reference to the material mode by which it is brought about; for materiality is still more an essential condition than absolute novelty. In fact, a patent can only be obtained in respect of a process or an apparatus; the vendible result is but the accidental or tangible representation of the thing: the patent itself is in respect of the novelty of the material, or of the novelty of the combination or process by which that vendible result is produced.

Now there is no pretext for saying that a patent can be taken out for cutting off legs whilst the patient is in a state of insensibility, or the mesmeric quacks might patent their manual flourishes and passes; nor could a patent be obtained for the mere administering of ether, for that is common, both as a medicine and a toy. Can there, then, be a patent for administering ether by inhalation, so as to produce insensibility? Can you patent the administration of jalap till a given effect is produced on the bowels? That is the reductio ad absurdam to which we are driven. Take the highest ground, and say that the effect is to be produced invariably by a given fixed quantity; you might as well try to patent a definite number of grains of rhubarb; or a publican might as well try to patent a certain proportion of Gordon's gin to a definite quantity of hot water and sugar, and call it a patent inebriator. But the question need not be argued so high as that: the inhalatiou must vary with the constitution of the patient; and the adminis. tration itself must be a matter of skill in the hands of those employing it. That is decisive of the question. The discovery is, that insensibility can be produced by a lnown medicine, so to call it, administered, by a known process, up to a certain point; that is an accidental fact, of great valne, certainly, but it is not a vendible result. If, indeed, the discoverer has any novel method of generating the gas, or any novel apparatus for administering it, both may be patented; but it will be open to the faculty to employ every other method, whether now known and generally usch, or which may be hereafter contrived by the application of their abundant scientific knowledge, and of the mechanical skinll of the many able men who construct instruments for the medical profession. I am Sir, your obedient servant,

Smith-square, Westminster, Jan. 1837.

J. B. Kincton.

"Medicine has for centuries served as the prop to natural science-a benefit which the latter has repaid by making the other feel its superiority."-Professor Marx. 